\title{
RISK, EXPECTED RETURN, AND THE COST OF EQUITY CAPITAL
}

\section{Glenn Boyle*}

NZ Institute for the Study of Competition and Regulation

Victoria University of Wellington

PO Box 600, Wellington

glenn.boyle@vuw.ac.nz

fax 044635560

25 September 2005

\begin{abstract}
In applying the CAPM to cost of capital calculations, practitioners treat the market risk premium as a free parameter to be estimated from data. However, this process ignores equilibrium in the cash market and therefore the implications of the CAPM for the premium itself. Full equilibrium relates the premium to underlying fundamental parameters, a finding that holds out the promise of identifying time-variation in the cost of capital. Unfortunately, this yields extremely volatile cost of capital estimates, thereby casting doubt on the risk-return tradeoff specified by the CAPM.
\end{abstract}

JEL classification: G11, G12, G31, G38

* I am grateful to Russell Investment Group Ltd for providing me with data used in this study; to Paul Hocking, Martin Lally, Leo Krippner, Abdullah Mamum, Alireza Tourani-Rad, and NZ Finance Colloquium and ISCR seminar participants for helpful comments; and to Hanqing Wang for invaluable research assistance. The responsibility for any remaining errors or ambiguities is mine alone. 


\section{RISK, EXPECTED RETURN, AND THE COST OF EQUITY CAPITAL}

\section{Introduction}

An important determinant of investment expenditure is the cost of the capital employed in undertaking investment. For firms considering a specific project, the cost of capital is the discount rate used to put all future cashflows on a common footing, thereby allowing assessment of the project's profitability. For regulators such as the New Zealand Commerce Commission, the cost of capital effectively determinines the price path a regulated firm is required to follow and thus has significant implications for the firm's incentives to invest.

Unfortunately, the cost of the equity component of capital is not directly observable and hence must be estimated from a theoretical model, the most commonly used of which is the celebrated Capital Asset Pricing Model (CAPM). ${ }^{1}$ The standard version of the CAPM has the familiar form:

$$
E\left[R_{i}\right]=R_{f}+\beta_{i}\left\{E\left[R_{m}\right]-R_{f}\right\}
$$

where $R_{i}$ is the random return on asset $i, R_{f}$ is the riskless rate of interest, $R_{m}$ is the random rate of return on the market portfolio of risky assets, $\beta_{\mathrm{i}}$ is the asset $\mathrm{i}$ 'beta', equal to the covariance of $\mathrm{R}_{\mathrm{i}}$ and $\mathrm{R}_{\mathrm{m}}$ divided by the variance of $\mathrm{R}_{\mathrm{m}}$, and $\mathrm{E}$ [.] is the expectations operator. Equation (1) states that the asset i risk premium is proportional to the market risk premium where the factor of proportionality is equal to $\beta_{\mathrm{i}}$. In this formulation, $\beta_{\mathrm{i}}$ is the quantity of asset $\mathrm{i}$ risk and the market risk premium $\left\{\mathrm{E}\left[\mathrm{R}_{\mathrm{m}}\right]-\mathrm{R}_{\mathrm{f}}\right\}$ is the price of that risk.

Equation (1) is a relative pricing model. Specifically, it relates one market price (the risk premium on asset $\mathrm{i}$ to another market price (the risk premium on the market portfolio). But the second price, if correctly measured, incorporates the first price, so there is an element

1 For example, Graham and Harvey (2001) report that $73.5 \%$ of United States CFOs "always or almost always" use the CAPM for estimating the cost of equity capital. An older survey by Patterson (1989) based on a much smaller sample finds that $38 \%$ of NZ firms do the same. Examples of the NZ Commerce Commission's dependence on the CAPM can be found on its website (www.comcom.govt.nz). 
of circularity in this process. Practical applications of the CAPM, such as estimating the cost of capital, typically ignore this problem - on the grounds that any individual asset is an infitesimally-small portion of the market portfolio - and treat the market risk premium as a free parameter to be estimated from data. ${ }^{2}$ But as Cochrane (2001) points out, this procedure ignores the CAPM predictions for the market portfolio itself; taking the market premium as given neglects its underlying dependence on more fundamental CAPM parameters.

The implications of this argument are explored in the remainder of the paper, but an intuitive overview may be helpful. Underlying the CAPM is the separation result from modern portfolio theory that all investors optimally allocate their funds between two portfolios, one risky and one riskless. Investor-specific risk attitudes determine the split between the two portfolios, but have no effect on the composition of the risky asset portfolio which depends only on the distribution of future asset returns. If all investors perceive the same returns distribution, they must then wish to hold the same portfolio of risky assets. Equilibrium in the market for these assets requires that this common portfolio be the socalled market portfolio, an observation that leads directly to equation (1). However, this process makes no explicit reference to equilibrium in the market for riskless assets. Incorporating this additional condition in the model places an exact restriction on the allowable value of the market risk premium in terms of the underlying variance of market returns. As a result, applications of the CAPM need only estimate the value of the latter parameter and not the market risk premium itself.

The link between the market risk premium and the returns variance is not in itself new. Assuming quadratic utility, or exponential utility with normal returns, (e.g., Friend and Blume,1975; Huang and Litzenberger, 1988), or continuous trading opportunities (Merton, 1980), other authors have also shown that the market risk premium is proportional to the variance of market returns. However, I demonstrate that this result is a simple consequence of riskless asset equilibrium, for all preferences defined over the mean and variance of singleperiod wealth, and that additional assumptions about utility or the returns structure are unnecessary. Perhaps more importantly, I examine the implications of the result for practical

2 See, for example, Lally (2004). 
applications such as estimating the cost of equity capital, an issue that none of the authors above, with the partial exception of Merton, considers .

Expressing the market risk premium as a function of the variance of market returns is potentially valuable for calculating the cost of capital. Estimating the variance of returns is much easier than estimating the mean, particularly when these parameters vary through time, so the alternative approach holds out the promise of identifying risk-based shifts in the cost of capital. Unfortunately, I find that the estimated variance of returns in New Zealand data is extremely volatile; at times the implied cost of capital is implausibly high while at other times it is implausibly low. In my view, this is not good news for CAPM-based approaches to estimating the cost of capital: seemingly-reasonable estimates based on (1) are obtained only by ignoring an important part of CAPM content.

The next section explicitly derives the link between the market risk premium and the variance of market returns. In Section 3, I discuss how this might help obtain more accurate cost of capital estimates and apply this to data. The final section contains some concluding remarks.

\section{CAPM and equilibrium in the market for riskless assets}

Let $R_{i}$ be the random return on risky asset $i=1, \ldots, n$ and $R_{f}$ be the certain return on a riskless asset. If $\lambda_{\mathrm{ik}}$ is expenditure on asset $\mathrm{i}$ by investor $\mathrm{k}=1, \ldots, \mathrm{m}$, and $\lambda_{\mathrm{fk}}$ is expenditure on the riskless asset, then end-of-period wealth $\mathrm{W}_{\mathrm{k}}$ satisfies:

$$
\mathrm{W}_{\mathrm{k}}=\sum_{\mathrm{i}=1}^{\mathrm{n}} \lambda_{\mathrm{ik}}\left(1+\mathrm{R}_{\mathrm{i}}\right)+\lambda_{\mathrm{fk}}\left(1+\mathrm{R}_{\mathrm{f}}\right)
$$

The asset expenditures must sum to initial wealth $\mathrm{W}_{0 \mathrm{k}}$. Setting the latter to unity for convenience, (2) can be written as:

$$
\mathrm{W}_{\mathrm{k}}=1+\mathrm{R}_{\mathrm{f}}+\sum_{\mathrm{i}=1}^{\mathrm{n}} \lambda_{\mathrm{ik}}\left(\mathrm{R}_{\mathrm{i}}-\mathrm{R}_{\mathrm{f}}\right)
$$


so that:

$$
\begin{aligned}
& \mathrm{E}\left[\mathrm{W}_{\mathrm{k}}\right] \equiv \overline{\mathrm{W}}_{\mathrm{k}}=1+\mathrm{R}_{\mathrm{f}}+\sum_{\mathrm{i}=1}^{\mathrm{n}} \lambda_{\mathrm{ik}}\left(\mathrm{E}\left[\mathrm{R}_{\mathrm{i}}\right]-\mathrm{R}_{\mathrm{f}}\right) \\
& \operatorname{var}\left(\mathrm{W}_{\mathrm{k}}\right) \equiv \mathrm{\sigma W}_{\mathrm{k}}={ }_{\mathrm{i}=1}^{\mathrm{n}} \sum_{\mathrm{j}=1}^{\mathrm{n}} \lambda_{\mathrm{ik}} \lambda_{\mathrm{jk}} \operatorname{cov}\left(\mathrm{R}_{\mathrm{i}}, \mathrm{R}_{\mathrm{j}}\right)
\end{aligned}
$$

Each investor has a utility function $v_{k}\left(\bar{W}_{k}, \sigma^{2} W_{k}\right)$ that depends only on the mean and variance of end-of-period wealth, and chooses the portfolio that maximises the value of this function:

$$
\underset{\left\{\lambda_{1 \mathrm{k} \cdots} \ldots \lambda_{\mathrm{nk}}\right\}}{\operatorname{Max}} \quad \mathrm{v}_{\mathrm{k}}\left(\overline{\mathrm{W}}_{\mathrm{k}}, \underset{\sigma \mathrm{W}_{\mathrm{k}}}{2}\right)
$$

The first-order conditions for this problem are:

$$
\gamma_{k}\left(E\left[R_{i}\right]-R_{f}\right)=\sum_{j=1}^{n} \lambda_{j k} \operatorname{cov}\left(R_{i}, R_{j}\right) \quad i=1, \ldots, n
$$

where $\gamma_{\mathrm{k}} \equiv-\frac{\partial \mathrm{v}_{\mathrm{k}} / \partial \overline{\mathrm{W}}_{\mathrm{k}}}{2\left(\partial \mathrm{v}_{\mathrm{k}} / \partial \sigma \mathrm{W}_{\mathrm{k}}\right)}$ is investor $\mathrm{k}$ 's marginal rate of substituting risk for return. That is, $1 / \gamma_{\mathrm{k}}$ is the additional mean return that investor $\mathrm{k}$ would need to be no worse off following a marginal increase in variance. If this is high (low), then investor $\mathrm{k}$ is relatively intolerant (tolerant) of risk. We can therefore interpret $1 / \gamma_{k}$ as a measure of investor $k$ 's risk aversion.

Writing (6) in matrix form and rearranging yields the two-fund separation result of Tobin (1958), i.e., the composition of investor k's portfolio of risky assets is unaffected by risk attitudes $\left(\gamma_{k}\right)$ and depends only on perceived means, variances and covariances of returns. If these parameters are the same for all investors, then they all hold the same portfolio of risky assets. Market clearing requires that this portfolio contain each asset in an amount equal to its weight in the portfolio of total invested wealth in risky assets, i.e., the 
market portfolio of risky assets. Then $\lambda_{\mathrm{jk}}$ is equal to asset $\mathrm{j}$ 's weight in this portfolio multiplied by investor k's total investment in risky assets $\left(1-\lambda_{\mathrm{fk}}\right)$ and equation (6) can be rewritten as:

$$
\gamma_{k}\left(E\left[R_{i}\right]-R_{f}\right)=\left(1-\lambda_{f k}\right) \operatorname{cov}\left(R_{i}, R_{m}\right) \quad i=1, \ldots, n
$$

where $R_{m}$ is the return on the market portfolio of risky assets.

As (7) holds for all risky assets, it must also apply to the market portfolio:

$$
\gamma_{\mathrm{k}}\left(\mathrm{E}\left[\mathrm{R}_{\mathrm{m}}\right]-\mathrm{R}_{\mathrm{f}}\right) \quad=\quad\left(1-\lambda_{\mathrm{fk}}\right) \sigma_{\mathrm{m}}^{2}
$$

where $\sigma_{m}^{2}$ is the variance of $R_{m}$. Combining (7) and (8) then yields equation (1):

$$
E\left[R_{i}\right]=R_{f}+\beta_{i}\left(E\left[R_{m}\right]-R_{f}\right)
$$

Equation (1) is, of course, the standard formulation of the CAPM, but it overlooks an important part of the underlying pricing process. Going from (6) to (7) requires that supply equal demand for each risky asset, but no corresponding requirement is imposed on the riskless asset.

To determine the implications of imposing riskless asset equilibrium, return to equation (8) and note that this can be written as

$$
\lambda_{\mathrm{fk}}=1-\frac{\left(\mathrm{E}\left[\mathrm{R}_{\mathrm{m}}\right]-\mathrm{R}_{\mathrm{f}}\right) / \sigma_{\mathrm{m}}^{2}}{\left(1 / \gamma_{\mathrm{k}}\right)}
$$

which expresses investor $\mathrm{k}$ 's demand for the riskless asset as a function of risk aversion and market portfolio characteristics. Intuitively, $\left(E\left[R_{m}\right]-R_{f}\right) / \sigma_{m}^{2}$ is the rate at which the market portfolio trades off risk and return while $\left(1 / \gamma_{\mathrm{k}}\right)$ is the rate at which investor $\mathrm{k}$ is willing to make this tradeoff. If, for example, the former exceeds the latter, then investor $\mathrm{k}$ desires 
more risk than is offered by the market portfolio alone and thus borrows at rate $\mathrm{R}_{\mathrm{f}}$ to finance a larger holding of that portfolio, i.e., $\lambda_{\mathrm{fk}}<0$.

Equilibrium in the riskless asset market requires that total borrowing equal total lending, i.e., $\sum_{\mathrm{k}=1}^{\mathrm{m}} \lambda_{\mathrm{fk}}=0 .{ }^{3}$ Applying this to (9) yields:

$$
\begin{aligned}
E\left[R_{m}\right]-R_{f} & =\left(\sum_{k=1}^{m} \gamma_{k} / m\right)^{-1} \stackrel{2}{\sigma_{m}} \\
& =(1 / \gamma) \sigma_{m}^{2}
\end{aligned}
$$

where $\gamma \equiv \sum_{\mathrm{k}=1}^{\mathrm{m}} \gamma_{\mathrm{k}} / \mathrm{m}$ is the average value of $\gamma_{\mathrm{k}}$, i.e., $1 / \gamma$ is the average risk aversion of all investors. Thus, equation (10) states that riskless asset equilibrium constrains the market risk premium to a value equal to the product of market risk and market risk aversion. To understand (10) intuitively, suppose that it is not satisfied, e.g., $\left(E\left[R_{m}\right]-R_{f}\right)<(1 / \gamma) \sigma_{m}^{2}$. Then the rate at which the market portfolio offers to trade off risk and return is below the rate required by investors to make this tradeoff. Investors will thus wish to substitute from the market portfolio to the riskless asset, i.e., there is excess demand for the riskless asset. With supplies fixed, equilibrium is re-established by a rise in $\left(E\left[R_{m}\right]-R_{f}\right)$ until the excess demand is eliminated. This occurs only when the available risk-return tradeoff is equal to the required tradeoff, i.e., when (10) holds. More succinctly, any violation of (10) implies excess demand or supply in the riskless asset market, so equilibrium in that market requires that (10) be satisfied. In equilibrium, the market risk premium $\left(E\left[R_{m}\right]-R_{f}\right)$ must equal the "market price of risk" $\left(\sigma_{\mathrm{m}}^{2} / \gamma\right)$.

Substituting equation (10) into (1) yields:

$$
E\left[R_{i}\right]=R_{f}+\beta_{i}\left(\sigma_{m}^{2} / \gamma\right)
$$

3 This assumes the riskless asset is in zero net supply. Nothing substantative in what follows is lost by allowing for a positive net supply. 
which relates the expected excess return on asset $\mathrm{i}$ to beta and the market price of risk.

The link between (1) and (11) is worth emphasizing. Equation (1) requires only that risky asset markets clear, and is thus a partial equilibrium statement that relates one endogenous price variable $\left(E\left[R_{i}\right]-R_{f}\right)$ to another $\left(E\left[R_{m}\right]-R_{f}\right)$. Equation (11) takes this insight a step further by requiring that supply also equal demand for the riskless asset, thereby allowing $E\left[R_{m}\right]-R_{f}$ to be expressed in terms of underlying exogenous paramaters and transforming (1) into a general equilibrium statement.

Friend and Blume (1975) and Merton (1980) also report an equation similar to (11), and Huang and Litzenberger (1988) explicitly derive it in the context of either quadratic utility or exponential utility with normal returns. However, none explicitly makes the link to riskless asset equilibrium, and only Merton recognises its implications for practical applications such as estimating the cost of capital. The latter issue is the subject of the remainder of this paper.

\section{Estimating the cost of capital}

Suppose one wishes to estimate a firm's cost of equity capital. ${ }^{4}$ The usual approach estimates the market risk premium $E\left[R_{m}\right]-R_{f}$ as a free parameter and uses this in equation (1), along with estimates of $\beta_{\mathrm{i}}$ and $\mathrm{R}_{\mathrm{f}}$. However, as section 2 demonstrates, the market risk premium is not a free parameter; rather it is an endogenous function of underlying CAPM parameters, as described by (10). Thus, applications of the CAPM can, in principle, use either (1) or (11), estimating either the market risk premium $\left(E\left[R_{m}\right]-R_{f}\right)$ or the market price of risk $\left(\sigma_{\mathrm{m}}^{2} / \gamma\right)$. Although the latter approach is theoretically superior, the only relevant consideration in practical situations is the reliability of estimates. More precisely, is it better to estimate the market risk premium or the market price of risk?

There are two reasons to favour the latter approach. First, as discussed at length by Merton (1980), Black (1993) and Campbell et al (1997), it is much easier to estimate the variance of returns than it is to estimate expected returns. The essence of their argument is

4 Somewhat loosely, I heneceforth use 'cost of capital' as a shorthand convenience for 'cost of equity capital'. 
that the precision of the variance estimate increases with the number of observations while the precision of the expected return estimate increases only with the length of the data series. In other words, a good estimate of variance can be obtained even with a short time series so long as the data are sufficiently high-frequency, but the only way to get a similarly good estimate of the mean is to have a long time series. Consequently, given the usual constraints on available data, variance estimates will be considerably more accurate than expected return estimates.

The second reason for favouring (11) follows from the first. In calculating the cost of capital, the relevant distribution of returns is the conditional distribution, since it is this that describes the current risk outlook: if risk is high at a particular date, then the market risk premium, and hence the cost of capital, should also be high at that date. More precisely, if one wishes to use equation (1) to estimate the cost of capital, then an estimate of the current market risk premium is required (i.e., the conditional mean of excess market returns); equation (11) requires, instead, an estimate of current risk (i.e., the conditional variance of market returns). In the case of (1) however, because of the long time period needed to estimate expected returns, the best one can feasibly do is obtain a single estimate of the unconditional market risk premium. Consequently, applications of (1) are unable to incorporate variation over time in the market risk premium and thus do not reflect the current risk environment. ${ }^{5}$ By contrast, equation (11) is potentially able to identify this variation because of the shorter time series required for estimating variance.

Of course, there is also a significant disadvantage to using (11): the parameter $\gamma$ is unobservable. However, it may be possible to estimate this fairly accurately. First, it seems reasonable to assume, at least as a first approximation, that $1 / \gamma$ is a constant; as Campbell and Viceria (2002) point out, there have been large increases in per capita consumption and

5 This problem also applies to so-called forward-looking methods of estimating the market risk premium that require historical averages of dividend yields and growth; see, for example, Claus and Thomas (2001) and Fama and French (2002). As Fama and French point out, this approach is not well suited to estimating the conditional risk premium. Other forward-looking methods that utilise analyst forecasts do allow for time variation in the premium, but do not explicitly relate this variation to risk shifts. 
wealth in the last 100 or so years, but no corresponding trends in risk premia or interest rates consistent with investors having changed their attitudes towards relative risks. Second, rearranging (10) shows that $1 / \gamma$ equals the ratio of the market risk premium and the variance of market returns. Thus, given sufficient data to estimate the unconditional values of these two parameters, their ratio yields the constant $1 / \gamma$ applicable to a given market. This can then be used in a conditional version of (11) to estimate the current cost of capital. For example, suppose one obtains, from 100 years of data, estimates of $\left\{E\left[R_{m}\right]-R_{f}\right\}$ and $\sigma_{m}^{2}$ equal to 0.06 and 0.03 respectively. Then the implied value of $1 / \gamma$ is two and, from (11), the current (date t) expected return on asset $\mathrm{i}$ is $\mathrm{R}_{\mathrm{ft}}+2\left(\sigma_{\mathrm{mt}}^{2}\right) \beta_{\mathrm{it}}$, where the $\mathrm{t}$ subscripts denote date $\mathrm{t}$ values.

To provide a concrete illustration and assessment of this process, I use equation (10) to estimate an annual series for the New Zealand market price of risk over the last 30 years. This requires, first, estimation of $1 / \gamma$ as described above, and, second, annual estimates of $\sigma_{\mathrm{mt}}^{2}$. To calculate $1 / \gamma$, I use the recent study of Lally and Marsden (2004) on NZ returns during the 1931-2002 period. Their estimates of the unconditional values of $\left\{E\left[R_{m}\right]-R_{f}\right\}$ and $\sigma_{\mathrm{m}}^{2}$ imply a value of $1 / \gamma$ equal to $1.4 .^{6}$

Turning to the conditional value of $\sigma_{\mathrm{m}}^{2}$, I use monthly real stock returns on the NZ stockmarket since 1967 to calculate a moving average variance of returns for the 34 years from January 1970 to December 2003.7 Specifically, for each month during this period, I calculate the sample variance of returns over the previous 36 months. These monthly

6 Lally and Marsden (2004) report post-tax estimates of $\left\{E\left[R_{m}\right]-R_{f}\right\}$ and $\sigma_{m}^{2}$ equal to 0.074 and 0.059 respectively. However, their calculation of the former is with respect to bonds rather than bills. For the countries examined in Dimson et al (2002), this understates the market premium by approximately one percentage point. Hence, I add back this difference and use $1 / \gamma=0.084 / 0.059=1.4$.

7 The nominal returns data are obtained from the NZ Gross Index compiled by Russell Investment Group Ltd. I am grateful to Craig Ansley and Fiona Lintott for providing me with access to these data. Details of its construction can be found in Chay et al (1993). Nominal returns are deflated using movements in the CPI. 
variances are first multiplied by twelve and then averaged across the 12 months of each calendar year to obtain a single estimate of the conditional variance for each year. ${ }^{8}$

Combining these estimates of $\sigma_{\mathrm{mt}}^{2}$ with $1 / \gamma=1.4$ gives a time series of annual estimates of the market price of risk, and the results from this procedure are outlined in Figure 1 and Table 1. The former depicts the year-by-year variation in the market price of risk estimate; the latter summarises these data for both the full period and three sub-periods.

\section{Figure 1}

\section{Time-Variation in the Market Price of Risk}

This figure illustrates the 1970-2003 time variation in the New Zealand market price of risk $\sigma_{\mathrm{mt}}^{2} / \gamma$, where $\sigma_{\mathrm{mt}}^{2}$ is the time $\mathrm{t}$ conditional variance of market returns and $1 / \gamma$ is the risk aversion parameter for the average investor. For each month, $\sigma_{\mathrm{mt}}^{2}$ is calculated as the sample variance of returns over the previous 36-months and then converted to an annual figure. $\gamma$ is set equal to 1.4, based on Lally and Marsden (2004).

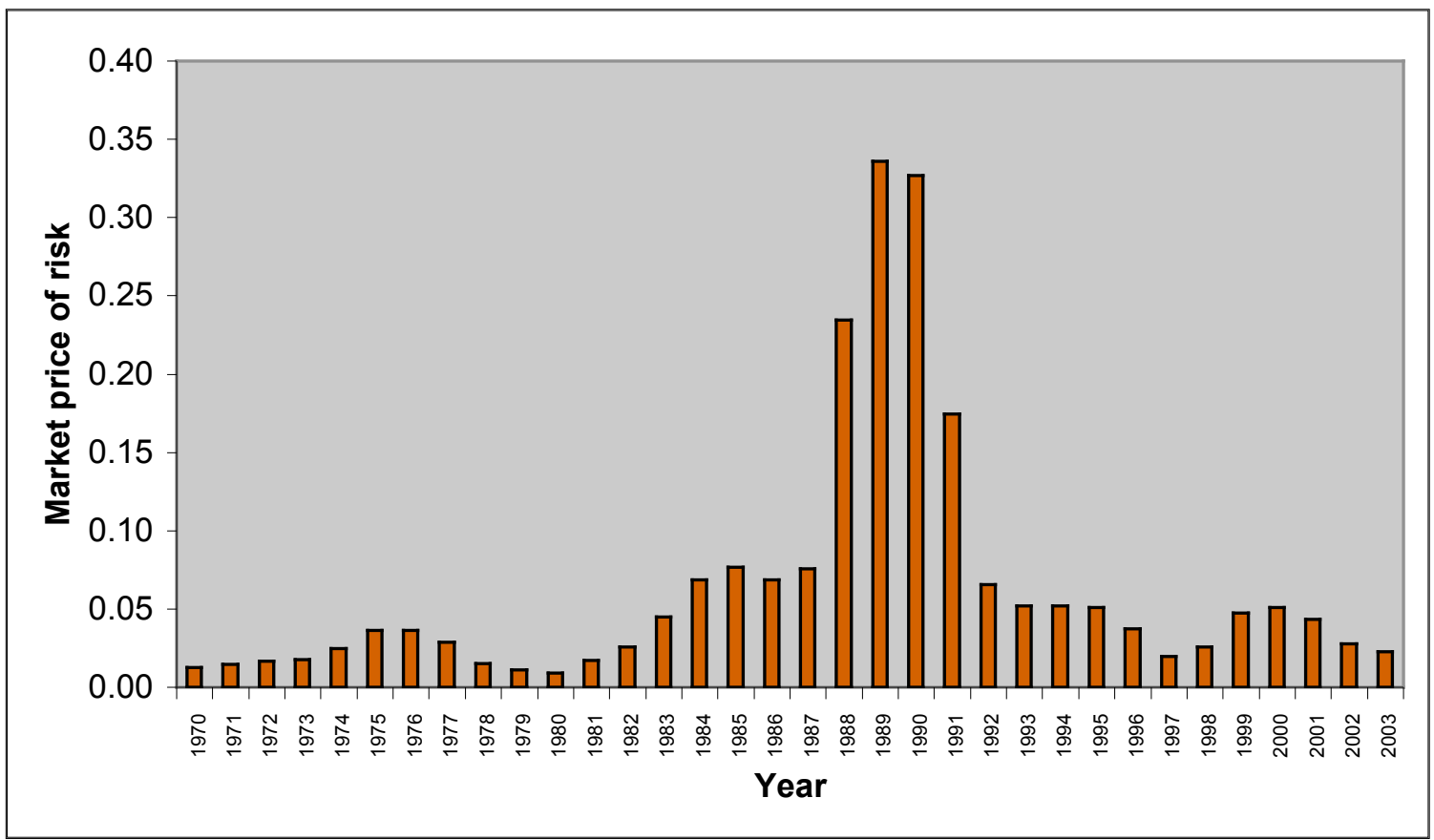

8 This simple procedure is similar to that used by Officer (1973), Merton (1980), and others. Averaging the squared returns (rather than calculating the sample variance), as those authors do, has essentially no effect on the results. An alternative approach is to estimate a GARCH process, e.g., Bollerslev (1986). As the latter method yields virtually identical conclusions in this case, I report only the simple approach described above. 


\section{Table 1}

\section{Time-Variation in the Market Price of Risk: Summary Statistics}

This table calculates the average, maximum and minimum values of the market price of risk series appearing in Figure 1.

\begin{tabular}{lccc}
\hline & Average & Maximum & Minimum \\
$\begin{array}{l}\text { Full Sample } \\
1970-2003\end{array}$ & 0.064 & 0.336 & 0.009 \\
& & & \\
Sub-Samples & 0.021 & 0.037 & 0.011 \\
$1970-79$ & 0.096 & 0.336 & 0.009 \\
$1980-89$ & 0.071 & 0.327 & 0.020 \\
$1990-2003$ & & & \\
\hline
\end{tabular}

The primary impression from these results is one of considerable volatility in the variance of market returns. For the period as a whole, the average market price of risk is a reasonablesounding $6.4 \%$, but this hides significant intra-period variation. ${ }^{9}$ Throughout the $1970 \mathrm{~s}$, the maximum value was $3.7 \%$ and the average only $2.1 \%$. In the $1980 \mathrm{~s}$, the price of risk ranged from less than $1 \%$ to more than $33 \%$; the period since 1990 is similarly volatile. Although the most extreme values occur in the 1980s, the remaining periods are also characterized by both high and low values. For the most recent year in the sample (2003), the estimated market price of risk is $2.3 \%$, implying a very low cost of capital for most projects.

If one wishes to use the CAPM to capture time variation in the market price of risk, these results are thought-provoking. For instance, is it really plausible that the price of risk went from less than $1 \%$ in the early part of the 1980 s to more than $30 \%$ by the end? Answering in the affirmative implies an acceptance of very large swings in the cost of

9 Interestingly, this figure is very similar to the mean market risk premium of $6.5 \%$ reported in the survey evidence of Lally et al (2004). 
capital. Similarly, does it seem reasonable that the average-risk firm (i.e., $\beta_{i}=1$ ) in 2003 had a cost of equity only 2.3 percentage points above the riskless rate of interest?

Measurement error in the two crucial variables $-\gamma$ and $\sigma_{m}^{2}$ - seems unlikely to resolve these problems. The volatility in $\sigma_{\mathrm{m}}^{2}$ is unaffected by the use of alternative estimation periods, higher-frequency data, or more sophisticated estimation methods. ${ }^{10}$ Similarly, any error in the estimate of $\gamma$ changes the market price of risk at each date, but has no effect on the volatility depicted in Figure 1. A more interesting possibility is that, contrary to the assumption maintained above, $1 / \gamma$ is not constant, but this seems likely to exacerbate matters: $1 / \gamma$ is most likely to be high when $\sigma_{\mathrm{m}}^{2}$ is high, and vice versa. ${ }^{11}$

If variable measurement error is not driving the results, then only two possibilities remain. One is that the true cost of capital is subject to much higher volatility, and takes on more extreme values, than has previously been thought. While this is by no means impossible (and the swings depicted in Figure 1 appear qualitiatively consistent with practitioners' ex-post assessment of time variation in the stock market's risk environment), movements of the kind described above would require a seismic change in mindset among managers and regulators used to dealing with a more-or-less constant cost of capital. The other possibility is that the simple product of $\gamma$ and $\sigma_{\mathrm{m}}^{2}$ fails to adequately capture the market price of risk. Or, to put it another way, the relationship between market risk and expected return is considerably more complex than envisaged by the CAPM. If one is sceptical about the first possibility, then the unpalatable conclusion is that the CAPM is incapable of relating the cost of capital to the contemporaneous risk environment. ${ }^{12}$

10 Although he does not discuss implications for cost of capital estimates, Merton's (1980) tables 4.7 and 4.8 indicate that similar volatility is present in US data. Thus, my results do not appear to be an artifact of NZ data. See also French et al (1987, Fig. 1a).

11 Of course, estimates of variance contain estimation error and are thus likely to be more volatile than true values. However, while this potentially rescues the theoretical validity of the CAPM pricing process, it simply re-states the practical problems.

12 According to this interpretation, my results are simply another manifestation of the lack of evidence for the CAPM tradeoff between risk and expected return (e.g., French et al, 1987; Campbell and Hentschel, 1992). 


\section{Concluding Remarks}

I interpret the results of this paper as bad news for practical applications of the CAPM. The usual approach takes the market risk premium as given and uses this, along with other exogenous parameters, to estimate the risk premium on some other asset or project. However, this suffers from two drawbacks. First, the market risk premium is an endogenous variable in CAPM equilibrium, so applications that treat it as exogoneous are effectively ignoring part of the CAPM. Second, because the market risk premium can only be accurately estimated using a long time series of data, the estimate used in applications is likely to reflect little of the current risk environment. The second problem can, in principle, be resolved by explitly dealing with the first so that the market risk premium is linked to the variance of market returns. Unfortunately, annual estimates of this risk parameter are extremely volatile, resulting in significant swings in the market risk premium. At the same time, the fact that market risk seems to vary through time at all is at odds with an approach that ignores the effect of risk on the market risk premium.

In short, the observed volatility in market risk casts doubt on the usual approach that implicitly assumes the market risk premium is a constant. But relaxing this assumption leads to the opposite problem: high variation in the market risk premium resulting in alternately high and low values of the cost of capital. Of course, some of this excessive variation is due to the extreme conditions of the 1980s, and it may be that the approach outlined in this paper will ultimately prove to work well in 'normal' conditions. But given the data that are currently available, the conventional usage of the CAPM in applications seems to largely reflect a willingness to ignore both empirical reality (time-variation in market risk) and theoretical consistency (the implications of the CAPM for pricing market risk). Most seriously of all, the inability of the CAPM to capture the relationship between risk and expected return in an empirically plausible manner must cast doubt on its suitability for cost of capital calculations. 


\section{References}

Black, F., 1993. Estimating expected return. Financial Analysts Journal 49, 36-38.

Bollerslev, T., 1986. Generalized autoregressive conditional heteroskedasticity. Journal of Econometrics 31, 307-327.

Campbell, J. and L. Hentschel, 1992. No news is good news: An asymmetric model of changing volatility in stock returns. Journal of Financial Economics 31, 281-318.

Campbell, J, A. Lo, and A.C. Mackinlay, 1997. The Econometrics of Financial Markets. New Jersey: Princeton University Press.

Campbell, J. and L. Viceira, 2002. Strategic Asset Allocation. Oxford: Oxford University Press.

Chay, J., A. Marsden and R. Stubbs, 1993. Historical rates of return to equities, bonds, and the equity risk premium: New Zealand evidence. Pacific Accounting Review 5, 27-46.

Claus, J. and J. Thomas, 2001. Equity premia as low as three percent? Evidence from analysts' earnings forecasts for domestic and international stock markets. Journal of Finance 56, 1629-1666.

Cochrane, J., 2001. Asset Pricing. Princeton: Princeton University Press.

Dimson, E., P. Marsh, and M. Staunton, 2002. Triumph of the Optimists. Princeton: Princeton University Press.

Fama, E. and K. French, 2002. The equity premium. Journal of Finance 57, 637-659.

French, K., G.W. Schwert and R. Stambaugh, 1987. Expected stock returns and volatility. Journal of Financial Economics 19, 3-29.

Friend, I. and M. Blume, 1975. The demand for risky assets. American Economic Review $65,900-922$.

Graham, J. and C. Harvey, 2001. The theory and practice of corporate finance: evidence from the field. Journal of Financial Economics 61, 187-243.

Huang, C. and R. Litzenberger, 1988. Foundations for Financial Economics. New York: Elsevier.

Lally, M., 2004. The weighted average cost of capital for gas pipeline businesses. NZ Commerce Commission. 
Lally, M. and A. Marsden, 2004. Tax-adjusted market risk premiums in New Zealand: 19312002. Pacific-Basin Finance Journal 12, 291-310.

Lally, M., M. Roush and T. van Zijl, 2004. The market risk premium in New Zealand. INFINZ Journal 1, 5-12.

Merton, R., 1980. On estimating the expected return on the market. Journal of Financial Economics 8, 323-361.

Officer, R., 1973. The variability of the market factor of the New York stock exchange. Journal of Business 46, 434-453.

Patterson, C., 1989. Investment decision criteria used by listed New Zealand companies. Accounting and Finance 29, 73-89.

Tobin, J., 1958, Liquidity preference as behavior towards risk, Review of Economic Studies, 65-86. 